\title{
Explosive volcanism on the ultraslow-spreading Gakkel Ridge, Arctic Ocean
}

Robert A. Sohn ${ }^{1}$, Claire Willis ${ }^{1}$, Susan Humphris ${ }^{1}$, Timothy Shank ${ }^{1}$, Hanumant Singh ${ }^{1}$, Henrietta N. Edmonds ${ }^{2}$, Clayton Kunz ${ }^{1}$, Ulf Hedman ${ }^{3}$, Elisabeth Helmke ${ }^{4}$, Michael Jakuba ${ }^{5}$, Bengt Liljebladh $^{6}$, Julia Linder ${ }^{4}$, Christopher Murphy ${ }^{1}$, Ko-ichi Nakamura ${ }^{7}$, Taichi Sato ${ }^{8}$, Vera Schlindwein $^{4}$, Christian Stranne ${ }^{6}$, Maria Tausenfreund ${ }^{4}$, Lucia Upchurch ${ }^{2}$, Peter Winsor ${ }^{1}$, Martin Jakobsson $^{9}$, Adam Soule ${ }^{1}$

${ }^{1}$ Woods Hole Oceanographic Institution, Woods Hole, MA, 02543, USA

${ }^{2}$ University of Texas at Austin Marine Science Institute, Port Aransas, TX, 78373, USA

${ }^{3}$ Swedish Polar Secretariat, SE 104 05, Stockholm, Sweden

${ }^{4}$ Alfred Wegener Institute for Polar and Marine Research, Bremerhaven, 27570, Germany

${ }^{5}$ Johns Hopkins University, Baltimore, MD, 21218, USA

${ }^{6}$ Göteborg University, Goteborg, 40530. Sweden

${ }^{7}$ AIST, Tsukuba Central 7, 1-1-1 Higashi, Japan

${ }^{8}$ Ocean Research Institute, University of Tokyo, Japan

${ }^{9}$ Stockholm University, 10691 Stockholm, Sweden

Roughly $60 \%$ of the Earth's outer surface is comprised of oceanic crust formed by volcanic processes at mid-ocean ridges (MORs). Although only a small fraction of this vast volcanic terrain has been visually surveyed and/or sampled, the available evidence suggests that explosive eruptions are rare on MORs, particularly at depths below the critical point for 
steam (3000 m). ${ }^{1}$ A pyroclastic deposit has never been observed on the seafloor below 3000 $\mathrm{m}$, presumably because the volatile content of mid-ocean ridge basalts is generally too low to produce the gas fractions required to fragment a magma at such high hydrostatic pressure. We employed new deep submergence technologies during an International Polar Year expedition to the Gakkel Ridge in the Arctic Basin at $85^{\circ} \mathrm{E}$, to acquire the first-ever photographic images of 'zero-age' volcanic terrain on this remote, ice-covered MOR. Our imagery reveals that the axial valley at $4000 \mathrm{~m}$ water depth is blanketed with unconsolidated pyroclastic deposits, including bubble wall fragments (limu o Pele), ${ }^{2}$ covering a large area greater than $10 \mathrm{~km}^{2}$. At least $13.5 \mathrm{wt} \% \mathrm{CO}_{2}$ is required to fragment magma at these depths, ${ }^{3}$ which is $\sim 10 \mathrm{x}$ greater than the highest values measured to-date in a MOR basalt. ${ }^{4}$ These observations raise important questions regarding the accumulation and discharge of magmatic volatiles at ultra-slow spreading rates on the Gakkel Ridge (6$14 \mathrm{~mm} \mathrm{yr}^{-1}$, full-rate), ${ }^{5}$ and demonstrate that large-scale pyroclastic activity is possible along even the deepest portions of the global MOR volcanic system.

The Gakkel Ridge, stretching 1800 km across the eastern Arctic Basin, is the ultraslow spreading end-member of the global mid-ocean ridge system, and in 1999 the Global Seismic Network (GSN) detected the largest MOR earthquake swarm in recorded history ${ }^{6}$ on the ridge at $85^{\circ} \mathrm{E}$. Several lines of evidence suggest that the swarm was associated with a major volcanic event, ${ }^{6-10}$ but our ability to characterize volcanic processes in this region has been limited by its remote location and ice cover. From July 15-31, 2007, the Arctic Gakkel Vents (AGAVE) expedition aboard the icebreaker Oden surveyed the presumed eruption site using a Kongsberg EM120 $1^{\circ} \times 1^{\circ}$ multi-beam echo sounder , a Conductivity-Temperature-Depth (CTD)/rosette, two autonomous underwater vehicles (AUVs), and a sub-ice camera and sampling platform (CAMPER). 
We produced a high-resolution bathymetric map of the axial valley floor at $85^{\circ} \mathrm{E}$ by operating the sonar system while drifting quiescently in the ice pack. The combination of the low-noise survey mode, and the variance reduction obtained from ping averaging several dozen overlapping tracklines, allowed us to produce a highly-detailed sonar image of the eruption site (Figure 1), showing that the axial valley is filled with highly distinctive volcanic features. These volcanoes are up to $2000 \mathrm{~m}$ in diameter by a few hundred meters high. They are commonly flattopped, contain a prominent central crater, and appear to cluster on ridge-parallel faults or fissures. The type example is perhaps Oden volcano, which is $\sim 300 \mathrm{~m}$ tall, $\sim 1.5 \mathrm{~km}$ diameter, and contains a $\sim 50$ m deep by $~ 500$ m diameter central crater (Figure 1).

A real-time, fibre-optic connection allowed scientists aboard the icebreaker to 'fly' the CAMPER vehicle 2-5 m above the seafloor within the region of the suspected eruption and acquire photographic still-imagery and high-definition video imagery of the volcanoes and the eruption site. Surprisingly, the images reveal that the axial valley topography is blanketed with unconsolidated pyroclastic deposits up to $10 \mathrm{~cm}$ thick. The thickest deposits overlie the weathered and broken lava flows (Figure 2a) on Jessica's Hill and Duque's Hill in the center of the axial valley (Figure 1), while the fresh (i.e., un-weathered, glassy, surfaces with delicate ornamentations) lava flows on the Oden and Loke volcanoes are covered with just a light dusting of material. Pyroclasts are piled atop pillows and other high-standing features, indicating deposition by fall rather than flow. Multiple falls are implied by spatial variations in the apparent age (color) and thickness of the deposits, and distinct boundaries between two or more deposits are evident in some places. The maximum extent of the pyroclastic material is not known, as the deposits were observed to cover every portion of the seafloor that we surveyed ( 20 linear km within a $\sim 5$ x $10 \mathrm{~km}$ region).

A series of eight dives across the Oden and Loke volcanoes suggests that the ubiquitous flat-topped volcanoes may be source vents for pyroclastic eruptions, possibly including 
vulcanian explosions. These volcanoes contain most of the fresh lava flows observed in our survey, which consist primarily of pillows, but also include ropey sheet flows, covering small areas $\left(\sim 100-200 \mathrm{~m}^{2}\right)$ on the top and around the outer edges of the constructional features. The mixture of young and old lava flows we observed demonstrates that the high-acoustic backscatter region imaged in 1999 does not represent a single, fresh lava flow. ${ }^{8}$ The crater of Oden volcano is filled with weathered, basaltic talus but contains no visible fault scarps. The talus is covered by small amounts of pyroclasts, and the block sizes generally decrease moving away from the crater center, extending onto the outer slopes of the volcano (Figure 2b). These observations are consistent with interpretation of the talus blocks as country rock ejecta from a vulcanian explosion, which may also play a role in crater formation, but at this point we cannot unequivocally rule out the possibility that the talus was formed by mass wasting.

Approximately $0.8 \mathrm{~kg}$ of clasts were collected from two sites along our tracklines using a retractable slurp (suction) device mounted on the CAMPER vehicle. The samples consisted nearly entirely of juvenile clasts of glassy basalt (Figure 2c) with a small $(<<5 \%)$ component of crystalline and altered crystalline rock. The clasts are primarily angular fragments, many with cuspate surfaces, that range in size from 1-20 $\mathrm{mm}$ (the suction sampler does not preserve in situ sorting). The clasts contain minor olivine and plagioclase microphenocrysts, and have low (< $5 \%)$ vesicularity. In addition, the deposits contain small amounts of limu o pele, ${ }^{2,11}$ which are thin, glassy, bubble wall fragments, 3-20 mm across, with fluidal folded morphologies (Figure 2d).

Large volume pyroclastic deposits have been found in shallow water (500-1750 m depth) on the Azores Plateau, ${ }^{12-14}$ but the only previous evidence of pyroclastic material at water depths greater than $3000 \mathrm{~m}$ (critical depth for steam) is limited to small fragments recovered in sediment cores. ${ }^{15,16}$ Hydrostatic pressure inhibits volume expansion, and below the steam threshold explosive activity must result from magmatic volatiles rather than secondary surface effects. $\mathrm{CO}_{2}$ 
is the most plausible exsolved volatile component for mid-ocean ridge basalts, ${ }^{15}$ and at $4000 \mathrm{~m}$ water depth a $\mathrm{CO}_{2}$ weight fraction of $\sim 14 \%^{3}$ is required to achieve the volume fraction of $\sim 75 \%$ required to fragment an erupting magma. ${ }^{17}$ This value exceeds the maximum dissolved $\mathrm{CO}_{2}$ concentrations measured in a mid-ocean ridge basalt ( $1.4 \mathrm{wt} \%$ in a 'popping rock') $)^{4}$ by an order of magnitude.

Volatiles that exsolve during magma ascent or decompression may coalesce to produce finite volumes of magma with gas volume fractions sufficient to trigger pyroclastic activity, even in magmas with primary volatile levels well below the fragmentation threshold. The nature of pyroclastic activity triggered by this process depends on the amount of volatiles and the depth where fragmentation occurs. For example, if gas exsolution and expansion occurs during the slow rise of an erupting dike, and the rising bubbles coalescence in the upper few hundred meters of the crust (i.e., slug flow), then Strombolian (bubble burst) activity may occur at the seafloor. The observation of bubble wall fragments in our pyroclastic samples is consistent with some level of Strombolian activity, but this mechanism distributes clasts to maximum distances of 20-40 m from the source vent, ${ }^{3}$ which is inconsistent with the widespread distribution of material over the $>10 \mathrm{~km}^{2}$ region observed in our survey.

A more energetic mechanism is required to deposit clasts more than a few tens of meters from the source vent, which is possible if fragmentation occurs deeper within the crust. The accumulation of volatiles as a foam layer within a magma chamber ${ }^{18}$ provides the most plausible mechanism for deep fragmentation. Exsolved volatiles may accumulate in a chamber over long periods of time, and then discharge explosively when the roof is fractured during an eruption, spreading pyroclastic material over large areas proportional to the chamber depth. For the range of parameters appropriate for our study area, we find that pyroclastic fountains may rise as high as $1-2 \mathrm{~km}$ in the water column if they are produced by the eruption of magmatic foams from a crustal chamber (Table 1). 
These results provide a new perspective for interpreting the 1999 seismic swarm and volcanic event at the $85^{\circ} \mathrm{E}$ site. The seismic swarm began with extensional events, but after three months the earthquakes changed to sources with large volume changes (implosions). ${ }^{6}$ Large volume change events are rare at MORs, but they are consistent with the explosive discharge of material from a deep-lying magma chamber. The sequence of extensional earthquakes leading up to the implosions may have perturbed the stress field enough to fracture the chamber roof, thereby releasing a pressurized magmatic foam. Rapid acceleration of decompressing volatiles may have triggered vulcanian explosions during the eruption, ${ }^{3}$ consistent with the talus distribution observed on Oden volcano. Multiple episodes of explosive volatile discharge over a prolonged period of time are required to produce the variations in apparent age and thickness of the deposits we observed, and we note that small-magnitude explosive acoustic signals were detected by local (ice-mounted) seismic networks at the eruption site more than two years after the 1999 seismic swarm. ${ }^{19}$ Explosive volatile discharge has clearly been a widespread, and ongoing, process at the $85^{\circ} \mathrm{E}$ segment.

Our results raise new questions regarding volatile processes in ultra-slow spreading magmatic systems. More observations are required to determine the ubiquity of pyroclastic activity at ultra-slow spreading rates ( $<15-20 \mathrm{~mm} \mathrm{yr}^{-1}$, full rate), but from first principles there is reason to believe that ultra-slow spreading ridges may be especially conducive to the build up and explosive discharge of volatile-rich magmatic foams. Long time intervals between eruptions should increase the amount of volatiles that can be accumulated in a magma chamber, and if the global correlation between spreading rate and magma chamber depth extends to ultra-slow rates, then volatile build-up will occur deep within the crust at high storage pressures. Our results add to the growing body of evidence that ultra-slow spreading ridges host unique modes of crustal accretion and tectonic extension, ${ }^{20,21}$ and motivate continuing efforts to solve the technical and logistical issues that have impeded scientific access to these unique geological environments. 
Table 1. Variation in pyroclastic jet characteristics with magma chamber depth.

\begin{tabular}{|c|c|c|c|c|}
\hline $\begin{array}{c}\text { Magma Chamber } \\
\text { Roof Depth, } \mathrm{m}\end{array}$ & $\begin{array}{c}\text { Minimum } \mathrm{CO}_{2} \\
\text { Volume Fraction } \\
\text { in Foam }\end{array}$ & $\begin{array}{c}\text { Pyroclastic Jet } \\
\text { Mixture Density } \\
\text { at Vent, } \mathrm{kg} / \mathrm{m}^{3}\end{array}$ & $\begin{array}{c}\text { Average Jet Exit- } \\
\text { Velocity at Vent, } \\
\mathrm{m} / \mathrm{s}\end{array}$ & $\begin{array}{c}\text { Plume Rise } \\
\text { Height in Water } \\
\text { Column, } \mathrm{m}\end{array}$ \\
\hline 1000 & 0.6443 & 568 & 236 & 544 \\
\hline 2000 & 0.5647 & 462 & 343 & 956 \\
\hline 3000 & 0.5026 & 398 & 424 & 1276 \\
\hline 4000 & 0.4528 & 355 & 490 & 1532 \\
\hline 5000 & 0.4120 & 324 & 544 & 1741 \\
\hline 6000 & 0.3779 & 302 & 591 & 1916 \\
\hline
\end{tabular}

Following the analysis presented in sections 2.4 and 2.5 of Head and Wilson (2003), we calculate the minimum $\mathrm{CO}_{2}$ volume fraction in a magmatic foam accumulating under the roof of a crustal magma chamber required to produce seafloor pyroclastic activity at a depth $=4000 \mathrm{~m}$. Magma chamber foams with the gas volume fractions shown in column 2 will fragment just before reaching the seafloor, producing very small deposits. However, if the $\mathrm{CO}_{2}$ volume fraction in the foam is $\sim 0.75$ then fragmentation occurs at the magma chamber depth, and a much more energetic eruption occurs as the gas accelerates during ascent to the seafloor, producing the approximate conditions shown in columns 3-5. 


\section{References}

1. White, J. D. L., Smellie, J. L. \& Clague, D. A. in Explosvie Subacqueous Volcanism (eds. White, J. D. L., Smellie, J. L. \& Clague, D. A.) 1-24 (American Geophyiscal Union, Washington, D.C., 2003).

2. Hon, K., Heliker, C. C. \& Kjargaard, J. I. Limu o Pele: A new kind of hydroclastic tephra from Kilauea Volcano, Hawai'i. Geol. Soc. Am. Abst. Prog. 20, A112-113 (1988).

3. Head, J. W. I. \& Wilson, L. Deep submarine pyroclastic eruptions: theory and predicted landforms and deposits. Journal of Volcanology and Geothermal Research 121, 155-193 (2003).

4. Javoy, M. \& Pineau, F. The volatiles record of a 'popping' rock from the Mid-Atlantic Ridge at $14^{\circ} \mathrm{N}$ : Chemical and isotopic composition of gas trapped in the vesicles. Earth and Planet. Sci. Lett. 107, 598-611 (1991).

5. Sella, G. F., Dixon, T. H. \& Mao, A. REVEL: A model for recent plate velocities from space geodesy. J. Geophys. Res. 107, doi:10.1029/2000JB000033 (2002).

6. Mueller, C. \& Jokat, W. Seismic Evidence for Volcanic Activity Discovered in Central Arctic. Eos Trans. AGU 81, 265,269 (2000).

7. Tolstoy, M., Bohnenstiehl, D. R., Edwards, M. H. \& Kurras, G. J. Seismic character of volcanic activity at the ultraslow-spreading Gakkel Ridge. Geology 29, 1139-1142 (2001).

8. Edwards, M. H. et al. Evidence of recent volcanic activity on the ultraslow-spreading Gakkel Ridge. Nature (London) 409, 808-812 (2001).

9. Edmonds, H. N. et al. Discovery of abundant hydrothermal venting on the ultra-slow spreading Gakkel Ridge in the Arctic Ocean. Nature 421, 252-256 (2003).

10. Graham, D. W. et al. Helium-3, methane, and manganese in water column hydrothermal plumes along the ultra-slow spreading Gakkel Ridge, Arctic Ocean. Ofioliti 31, 234-235 (2006).

11. Clague, D. A., Davis, A. S., Bischoff, J. L., Dixon, H. E. \& Geyer, R. Lava bubble-wall fragments formed by submarine hydrovolcanic explosions on Loihi Seamount and Kilauea Volcano. Volcano Bull. Volcanology 61, 437-449 (2000).

12. Eissen, J.-P., Fouquet, Y., Hardy, D. \& Ondreas, H. in Explosive subacqueous volcanism (eds. White, J. D. L., Smellie, J. L. \& Clague, D. A.) 143-166 (2003).

13. Fouquet, Y. et al. Extensive volcaniclastic deposits at the Mid-Atlantic Ridge axis; results of deep-water basaltic explosive volcanic activity? Terra Nova 10, 280-286 (1998).

14. Hekinian, R. et al. Deep sea explosive activity on the Mid-Atlantic Ridge near 3450'N: Magma composition, vesicularity, and volatile content. Journal of Volcanology and Geothermal Research 98, 49-77 (2000).

15. Clague, D. A., Davis, A. S. \& Dixon, J. E. in Explosive Subaqeous Volcanism (eds. White, J. D. L., Smellie, J. L. \& Clague, D. A.) 111-128 (American Geophysical Union, Washington, DC, 2003).

16. Clague, D. A., Uto, K., Satake, K. \& Davis, A. S. in Hawaiian Volcanoes: Deep Underwater Perspectives (ed. al.), E. T. e.) 65-84 (American Geophyiscal Union, Washington, D. C., 2002).

17. Sparks, R. S. J. The dynamics of bubble formation and growth in magmas: A review and analysis. J. Volcanol. Geotherm. Res. 3, 1-37 (1978). 
18. Bottinga, Y. \& Javoy, M. Mid-ocean ridge basalt degassing: Bubble nucleation. J. Geophys. Res. 95, 5125-5131 (1990).

19. Schlindwein, V., Müller, C. \& Jokat, W. Seismoacoustic evidence for volcanic activity on the ultraslow-spreading Gakkel Ridge, Arctic Ocean. Geophysical Research Letters 32, doi:10.1029/2005GL023767 (2005).

20. Dick, H. J. B., Lin, J. \& Schouten, H. An ultraslow-spreading class of ocean ridge. Nature 426, 405-412 (2003).

21. Michael, P. J. et al. Magmatism and amagmatic seafloor generation at the ultraslowspreading Gakkel Ridge, Arctic Ocean. Nature 423, 956-961 (2003).

22. Wessel, P. \& Smith, W. H. F. Free software helps map and display data. Eos Trans. AGU 72, 441 (1991).

23. Shank, T. M. et al. Biological and Geological Characteristics of the Gakkel Ridge. Eos Trans. AGU 88, Abstract OS41C-08 (2007).

Acknowledgments We thank David Clague and James Head III for reviews that improved the final manuscript, and the crew of icebreaker Oden for technical support at-sea. This research was funded by the National Aeronautics and Space Administration, the National Science Foundation, and the Woods Hole Oceanographic Institution.

Author Contributions R.A.S. was the chief scientist of the Arctic Gakkel Vents Expedition and wrote the paper. C.W. and A.S. analysed the dive imagery. M.J. processed the bathymetric data. S.H., T.S., H.S., H.N.E., C.K., U.H., E.H., M.J., B.L., J.L., C.M., K.N., T.S., V.S, C.S., M.T., L.U., and P.W. provided technical and scientific support at-sea. All authors discussed the results and provided input to the manuscript.

Author Information Reprints and permissions information is available at www.nature.com/reprints. The authors declare no competing financial interests. Correspondence and requests for materials should be addressed to R.A.S. (rsohn@whoi.edu). 


\section{Figure Captions}

Figure 1. Detailed bathymetry (30 m grid spacing) of the Gakkel Ridge at $85^{\circ} \mathrm{E}$ in the Arctic Ocean. Inset map shows the location of the $85^{\circ} \mathrm{E}$ segment (yellow star) along the Gakkel Ridge (red line) in the Arctic basin. Main panel shows illuminated, color bathymetry of the $85^{\circ} \mathrm{E}$ segment acquired during the AGAVE expedition. The axial valley contains large numbers of distinctive, cratered, volcanoes, including a cone on a fault terrace of the northern valley wall. Photographic bottom surveys were conducted along profiles shown as thin, black lines on the map. Pyroclastic deposit samples were collected at sites shown by white circles, and the photographs shown in Figure 2a and 2b were taken at the sites shown by the lettered, red, stars. Named features include two volcanic ridges in the center of the axial valley (Jessica’s Hill and Duque’s Hill), and three cratered volcanoes along a ridge-parallel fissure to the south (Oden, Thor, and Loke). The bathymetry data were plotted using Generic Mapping Tools. ${ }^{22}$

Figure 2. Photographs of pyroclastic deposits. (A). Frame grab from a high-definition video camera taken on the south side of Duque's Hill (see Figure 1 for location). Approximately $10 \mathrm{~cm}$ (visually estimated and confirmed during sampling) of pyrolcastic material is piled atop a highstanding, weathered, pillow feature. The exoskeleton of a to-this-point unidentified species of hexactinellid sponge ${ }^{23}$ is visible in the foreground. (B) High-definition video frame grab of talus blocks possibly representing ejecta from a vulcanian explosion on Oden volcano (see Figure 1 for location). (C) Glassy, granular, pyroclastic material. (D) Bubble wall fragment from pyroclastic deposit. 